ping clofibrate for the second time the EMG and biochemical changes disappeared once more.

This appears to be the first patient reported in which reversible EMG changes are demonstrated after repeated clofibrate administration.

\section{References}

Green, K.C. \& Margaretz, G. (1967) Long-term follow-up of multicentre trial of ethyl- $\alpha-p$-chlorphenoxyisobutyrate (Clofibrate, 'Atromid'-S) and Clofibrate Plus Andro- sterone ('Atromid'). Progress in Biochemical Pharmacology, $2,378$.

Katsilambros, Braaten, J.B., Ferguson, D. \& Bradley, R.F. (1972) Muscular syndrome after clofibrate. New England Journal of Medicine, 286, 1110.

LANGER, T. \& LeVY, R.I. (1968) Acute Muscular Syndrome associated with administration of clofibrate. New England Journal of Medicine, 279, 856.

Smith, A.F., Macfie, W.G. \& Oliver, M.F. (1970) Clofibrate serum enzymes and muscle pains. British Medical Journal, ii, 86.

Vester, J.W., SABEH, G. \& DANovski, T.S. (1969) No muscle damage from clofibrate. New England Journal of Medicine, $280,110$.

\title{
Asymptomatic autoimmune liver disease in scleroderma
}

\author{
M. M. GuPTA \\ M.D.
}

\author{
T. W. WARNES \\ M.R.C.P.
}

\author{
L. WATSON \\ F.R.A.C.P. \\ Metabolic Ward, University College Hospital, Gower Street, London
}

\begin{abstract}
Summary
A case is described of scleroderma with asymptomatic autoimmune liver disease. The patient presented with the features of CRST syndrome (calcinosis, Raynaud's phenomenon, sclerodactyly and telangiectasia) and a raised plasma alkaline phosphatase was found on routine investigation. It is suggested that this latter biochemical finding is likely to indicate associated autoimmune liver disease in patients with scleroderma.

\section{Introduction}

There have been sporadic reports dating back to 1934 of liver disease occurring in patients with scleroderma but the association occurs rarely. Thus D'Angelo et al. (1969) found more instances of cirrhosis in fifty-eight control patients than in fiftyeight patients with systemic scleroderma, while Bartholomew et al. (1964) found only eight examples of chronic liver disease in 727 cases of scleroderma and concluded that there was no relationship between the two diseases. In 1958, Calvert et al. described two cases of scleroderma with portal hypertension who bled from oesophageal varices; in the first case, liver biopsy was not performed and in the

\footnotetext{
Correspondence: Dr T. W. Warnes, Metabolic Ward,
} University College Hospital, Gower Street, London WC1 6AU.
\end{abstract}

second it showed only patchy fibrotic changes. In 1970, Reynolds et al. and Murray-Lyon et al. independently described the association of primary biliary cirrhosis with scleroderma. All the eight patients described by these workers had evidence of florid liver disease. In this paper we describe a case of CRST syndrome (calcinosis, Raynaud's phenomenon, sclerodactyly and telangiectasia) who had neither symptoms nor signs of liver disease. Elevation of plasma alkaline phosphatase led to further investigations. On fractionation, the isoenzyme was shown to be of hepatic origin whilst the presence of antimitochondrial, antinuclear and smooth muscle antibodies in the serum suggested an associated autoimmune liver disease, which was confirmed by the histological findings on liver biopsy. We shall discuss this in relation to the recent observations of Fox, Scheuer and Sherlock (1973) that primary biliary cirrhosis may now be diagnosed when asymptomatic.

\section{Case report}

In 1960, a 41-year-old woman developed sclerodermatous changes in the fingers of the left hand with localized areas of subcutaneous calcification. Similar changes then appeared in the right hand and during the next 4 years calcinosis also developed over the left wrist. She developed Raynaud's phenomenon in 
1968. She had never noted dysphagia, jaundice or pruritus. Clinical examination in February 1973 revealed bilateral sclerodactyly with calcinosis, typical Raynaud's phenomenon and two small telangiectases on her forehead. She was anicteric and there was no hepatosplenomegaly or any other sign of liver disease. There were no other abnormalities on physical examination. Her blood pressure was $130 / 70 \mathrm{mmHg}$.

Investigations. Radiological examination of both hands showed calcinosis circumscripta together with some tapering of the tips of the fingers and some calcinosis in the left wrist joint. Barium swallow showed a slightly dilated oesophagus which did not empty completely when the patient was supine; the motility was also diminished. Barium follow-up showed that the calibre of the proximal small bowel was at the upper limit of normal. Tests of pulmonary function were normal. The ECG showed a $Q$ wave in leads III and aVF consistent with an old inferior myocardial infarct. Plasma urea and creatinine were normal as was the creatinine clearance. Haematology was normal. Tests of liver function showed a plasma bilirubin of $0.9 \mathrm{mg} / 100 \mathrm{ml}$; plasma alkaline phosphatase $63 \mathrm{KA}$ units $/ 100 \mathrm{ml}$; plasma glutamic oxaloacetic transaminase $23 \mathrm{iu} / 1$ (normal up to $14 \mathrm{iu} / \mathrm{l}$ ), plasma glutamic pyruvic transaminase 23 iu/l (normal up to $10 \mathrm{iu} / \mathrm{l}$ ), albumin $3.9 \mathrm{~g} / 100 \mathrm{ml}$ and globulin $3.8 \mathrm{~g} / 100 \mathrm{ml}$. Electrophoresis showed moderate elevation of the gamma-globulin. The prothrombin index was normal. Plasma BSP test showed $23 \%$ retention at $45 \mathrm{~min}$ (normal less than $5 \%$ ). Separation of the isoenzymes of alkaline phosphatase by electrophoresis on polyacrylamide gel slabs (Anson and
Rowe, 1970) showed that the elevated alkaline phosphatase was of hepatic origin (Fig. 1). Serum IgG was $1880 \mathrm{mg} / 100 \mathrm{ml}$, IgM $720 \mathrm{mg} / 100 \mathrm{ml}$ and IgA $330 \mathrm{mg} / 100 \mathrm{ml}$. The serum cholesterol, triglycerides and lipoprotein pattern were all normal. The immunofluorescent technique for antinuclear factor was positive. Antinuclear antibodies were present in a titre exceeding $1 / 160$, smooth muscle antibodies were present at a dilution of 1 in 10 by immunofluorescence and antimitochondrial antibodies were present by immunofluorescence but gave a negative complement fixation titre. Rose Waaler test and rheumatoid slide latex tests were negative.

A needle biopsy (Figs 2 and 3) showed slight cholestasis and inflammatory cell infiltration about the portal system with bile ductule proliferation and reticulin increase which extended into lobules, disrupting the lobular pattern with isolation of groups of liver cells and possibly nodular regeneration. No definite liver cell necrosis was seen. No granulomata were observed. The histological appearances were those of autoimmune liver disease and were thought to be rather more compatible with active chronic hepatitis progressing to cirrhosis than with primary biliary cirrhosis.

Because of the subcutaneous calcification she was started on long-term treatment with probenecid up to $2 \mathrm{~g}$ daily as described by Dent and Stamp (1972). She was not given any treatment for the liver disease.

\section{Discussion}

The CRST syndrome (Winterbauer, 1964) is a well recognized variant of scleroderma, which frequently runs a benign course. Although liver disease

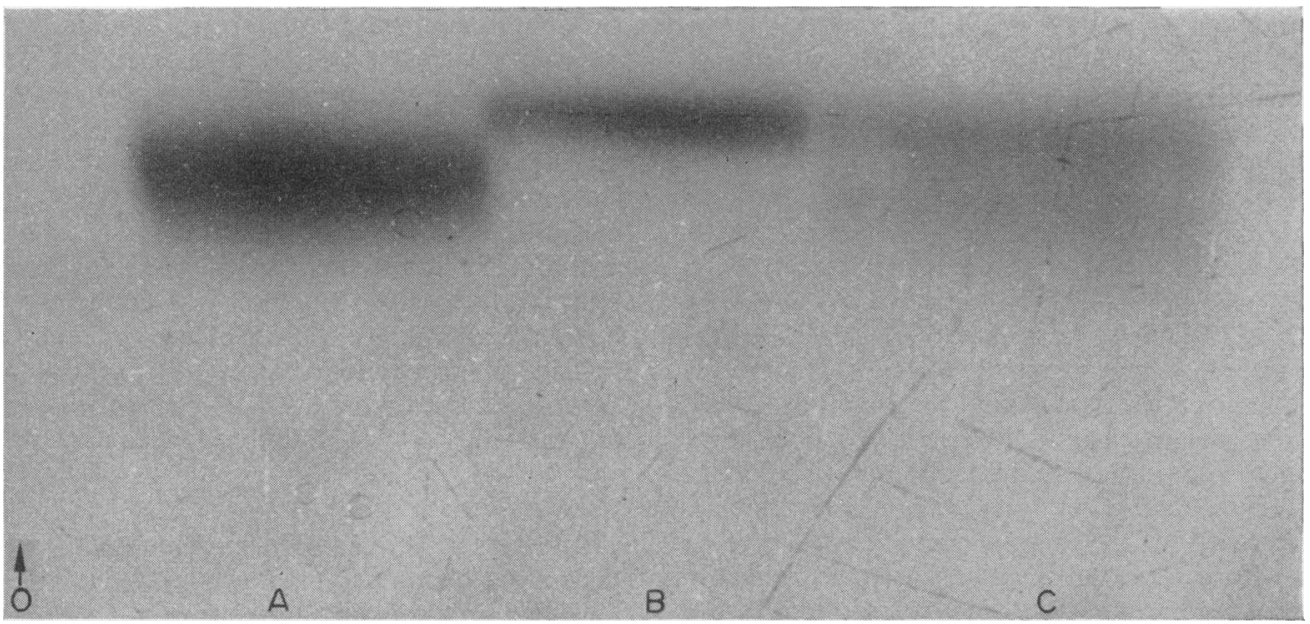

FIG. 1. Plasma alkaline phosphatase isoenzyme patterns on polyacrylamide gel slab electrophoresis. A, Patient with Paget's disease showing bone isoenzyme; B, present patient showing liver isoenzyme; $\mathrm{C}$, normal control showing both bone and liver isoenzymes. $\mathrm{O}$ marks the origin. 


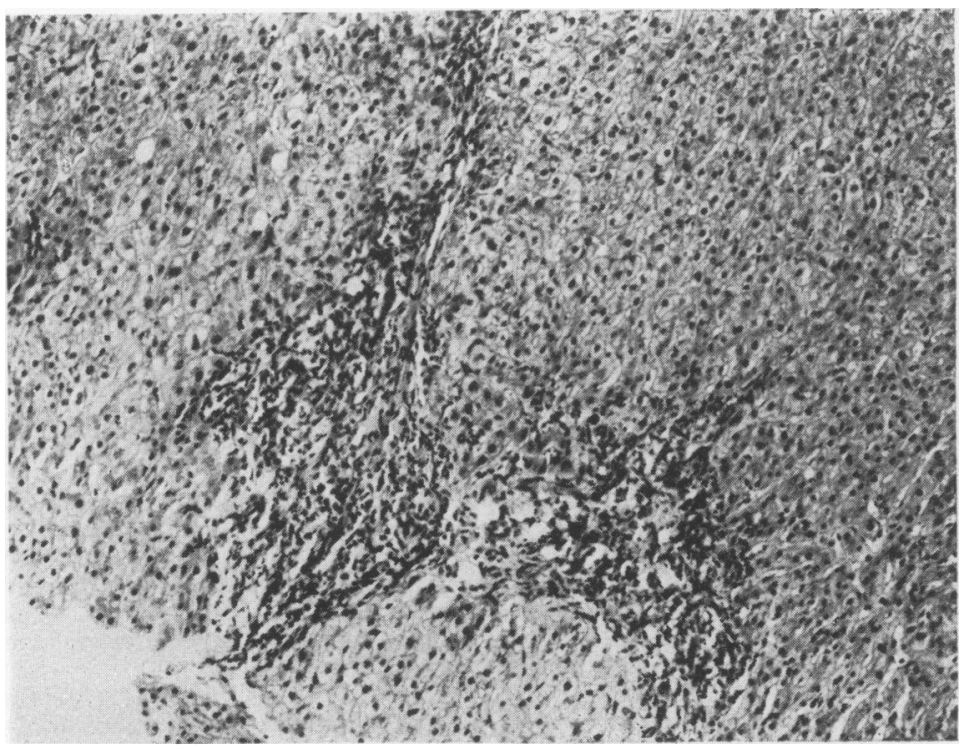

FIG. 2. Liver biopsy showing expansion of portal tracts by a chronic inflammatory infiltrate with some fibrosis and bile ductule proliferation (HE $\times 100)$.

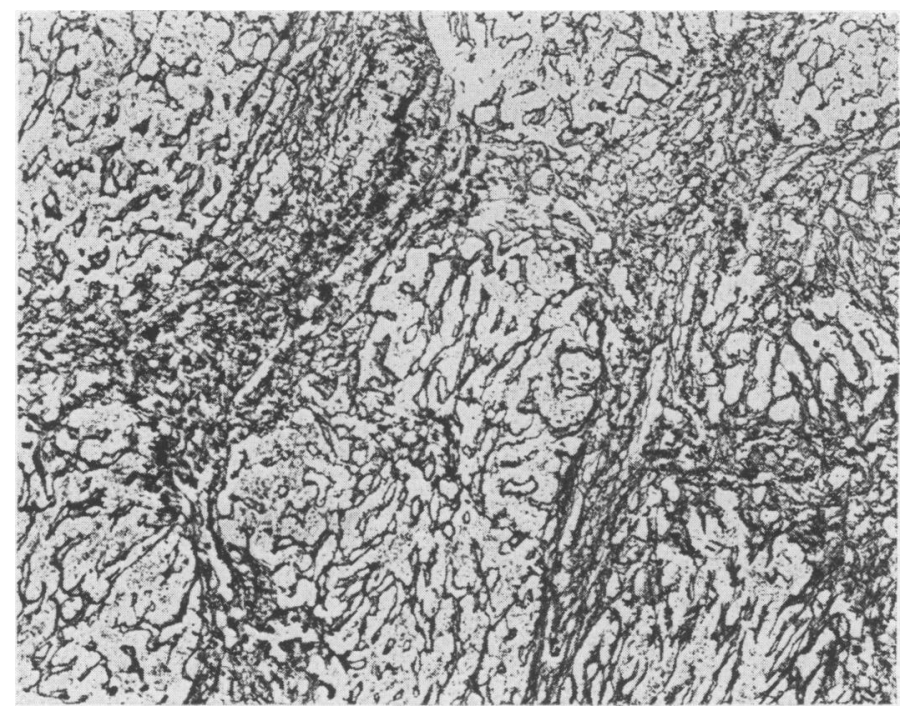

FIG. 3. Reticulin stain of the same liver biopsy showing destruction of normal architecture $(\times 100)$.

is thought to be rare in scleroderma, its association with primary biliary cirrhosis has been recently described. The two patients described by Murray-Lyon et al. (1970) presented with hepatosplenomegaly and one had features of CRST syndrome. All the six cases in the series of Reynolds et al. (1971) presented with pruritus and jaundice; three had hepatomegaly and splenomegaly. In both reports an elevated alkaline phosphatase and positive serum antimitochondrial antibody tests were constant features.

In the original description of primary biliary cirrhosis (Addison and Gull, 1851) the classical features 
were pruritus, jaundice, xanthomas, xanthelasmas, hepatosplenomegaly and skin pigmentation. Sherlock (1959) reported that $20 \%$ of the patients may not be jaundiced at the time of first diagnosis. Doniach and Walker (1969) have proposed a unified concept of autoimmune liver disease in which primary biliary cirrhosis, chronic active hepatitis and cryptogenic cirrhosis form a spectrum of one disease and may be aetiologically related.

Walker, Doniach and Doniach (1970) on screening a large number of hospital patients for antimitochondrial antibodies, detected thirty-five patients with subclinical liver disease and found minor histological changes in eight who were biopsied. Recently four asymptomatic patients with primary biliary cirrhosis have been reported (Fox et al., 1973). All these patients had elevated alkaline phosphatase levels and antimitochondrial antibodies in the serum together with compatible histological findings on liver biopsy. This latter report highlights the problem of defining the prognosis in primary biliary cirrhosis since the diagnosis can now be made during the asymptomatic or subclinical phase.

The histological findings on liver biopsy may not be diagnostic (Scheuer, 1967) for it is often difficult to distinguish chronic active hepatitis from primary biliary cirrhosis in the early stages. Similarly, the end stages of the condition may be indistinguishable from the end stage of cirrhosis due to other causes (Mackay and Wood, 1962). In the present patient, the same difficulty arose because the specimen on liver biopsy did not contain any medium sized bile ducts or granulomata. However, the presence of ANF, smooth muscle antibodies and antimitochondrial antibodies points to the existence of an autoimmune process in the liver.

Whilst treatment of chronic active hepatitis has been shown to improve the prognosis (British Medical Journal, 1973) there is no evidence for the efficacy of immuno-suppressive therapy in established primary biliary cirrhosis. Similarly, there is no evidence about the value of treatment in asymptomatic autoimmune liver disease and, therefore, we did not consider that therapy with steroids or azathioprine was indicated in this patient.

The true incidence of autoimmune liver disease in scleroderma is unknown and the present report clearly underlines that it may be quite asymptomatic. We suggest that routine measurement of the serum alkaline phosphatase in all patients with scleroderma is indicated as a simple screening procedure which would enable the true incidence of autoimmune liver disease in scleroderma to be established.

\section{Acknowledgments}

We wish to thank Professor C. E. Dent for his advice and comments, Mr D. Rowe for the electrophoretic studies, Dr P. M. Sutton for the histological interpretation and $\mathrm{Dr} \mathrm{D}$. Doniach for the antibody studies. M.M.G. gratefully acknowledges support from the Medical Research Council.

\section{References}

Addison, T. \& Gull, W. (1851) On a certain affection of the skin, vitiligoidea, $\alpha$ plana, $\beta$ tuberosa. Guy's Hospital Reports, 7, 265.

ANSON, R.C. \& Rowe, D.J.F. (1970) Electrophoretic separation of tissue specific serum alkaline phosphatases. Journal of Clinical Pathology, 23, 499.

Bartholomew, L.G., Cain, J.C., Winkelmann, R.K. \& Baggentass, A.H. (1964) Chronic disease of the liver associated with systemic scleroderma. American Journal of Digestive Diseases, 9, 43.

British Medical Journal (1973) Immuno suppressive therapy in active chronic hepatitis. iv, 441.

Calvert, R.J., Barline, B., Sopher, M. \& Fiewel, M. (1958) Systemic scleroderma with portal hypertension. British Medical Journal, i, 22.

D'Angelo, W.A., Fries, J.F., Masi, A.T. \& Shulman, L.E. (1969) Pathological observations in systemic sclerosis (scleroderma). American Journal of Medicine, 46, 428.

DENT, C.E. \& STAMP, T.C.B. (1972) Treatment of calcinosis circumscripta with Probenecid. British Medical Journal, i, 216.

Doniach, D. \& Walker, J.G. (1969) A unified concept of autoimmune hepatitis. Lancet, i, 813.

Fox, R.A., Scheuer, P.J. \& Sherlock, S. (1973) Asymptomatic primary biliary cirrhosis. Gut, 14, 444.

MACKAY, I.R. \& WooD, I.J. (1962) Lupoid hepatitis: a comparison of 22 cases with other types of chronic liver diseases. Quarterly Journal of Medicine, 31, 485.

Murray-Lyon, I.M., Thompson, R.H.P., Ansell, I.D. \& Williams, R. (1970) Scleroderma and primary biliary cirrhosis. British Medical Journal, iii, 258.

Reynolds, T.B., Denison, E.K., Frankl, H.D., Lieberman, F.L. \& Peters, R.L. (1970) Gastroenterology (Abstract), 58, 290.

Reynolds, T.B., Denison, E.K., Frankl, H.D., Lieberman, F.L. \& Peters, R.L. (1971) Primary biliary cirrhosis with scleroderma, Raynaud's phenomenon and telangiectasia. American Journal of Medicine, 50, 302.

Scheuer, P.J. (1967) Primary biliary cirrhosis. Proceedings of the Royal Society of Medicine, 60, 1257.

Sherlock, S. (1959) Primary biliary cirrhosis (chronic intra hepatic obstructive jaundice). Gastroenterology, 37, 574.

Walker, J.G., DoniaCh, D. \& DoniaCh, I. (1970) Mitochondrial antibodies and subclinical liver disease. Quarterly Journal of Medicine, 39, 31.

WiNTERBAUER, R.H. (1964) Multiple telangiectasia, Raynaud's phenomenon, sclerodactyly and subcutaneous calcinosis. A syndrome mimicking hereditary haemorrhagic telangiectasia. Bulletin of the Johns Hopkins Hospital, 114, 361. 